\title{
Analysis of fatigue notch effect due to axial misalignment for ultra high-strength steel butt joints
}

\author{
Markus J. Ottersböck ${ }^{1} \cdot$ Martin Leitner $^{1} \cdot$ Michael Stoschka ${ }^{1} \cdot$ Wilhelm Maurer $^{2}$
}

Received: 18 December 2017 / Accepted: 5 February 2019 / Published online: 13 March 2019

(C) The Author(s) 2019

\begin{abstract}
The majority of fatigue tests of welded specimens is based on shop-made samples generally exhibiting minor misalignment. Due to the challenge of ensuring misalignment-free joints in industrial manufacturing processes, investigations focussing on the effect of misalignment on the fatigue strength are important. Therefore, this paper deals with the influence of axial misalignment on the fatigue resistance of butt-welded ultra high-strength steel specimen. In addition, the effect of high frequency mechanical impact treatment (HFMI) on the fatigue performance is researched. In the course of the experimental investigations, specimens exhibiting three different levels of axial misalignment are manufactured. Fatigue tests at a stress ratio of $R=0.1$ in as-welded condition reveal a significant drop in fatigue strength with increasing axial misalignment. Fatigue assessments of the as-welded test results based on nominal, structural and effective notch stress approach are performed taking into account the sampledependent misalignment factor. The given equations enable an improved consideration of axial misalignment regarding to fatigue strength. The HFMI treatment increases the fatigue strength compared with the as-welded state; the detrimental effect of misalignment is less pronounced. A comparison to the current IIW guideline for HFMI treatment reveals a conservative assessment if IIW-recommended FAT values for as-welded condition are applied.
\end{abstract}

Keywords Fatigue strength $\cdot$ Ultra high-strength steel $\cdot$ Axial misalignment $\cdot$ HFMI treatment

\section{Introduction}

Within industrial manufacturing processes, weld seams usually exhibit a certain amount of angular and axial misalignment affecting the fatigue strength of welded structures in service. In contrast, the majority of welded specimens utilised for gathering fatigue test data is manufactured in workshop resulting in minor axial misalignment and angular distortion for every tested specimen. Thus, in many cases, the effect of misalignment on the fatigue strength of the weld detail is not well covered by experiment. This may be critical for applying such values without additional misalignment factors for fatigue assessment.

Recommended for publication by Commission XIII - Fatigue of Welded Components and Structures

Markus J. Ottersböck

markus@ottersboeck.at

1 Montanuniversität Leoben, Leoben, Austria

2 voestalpine Stahl GmbH, Linz, Austria
The offset between butt-welded sheets leads to an additional secondary bending moment significantly affecting the local stress distribution around the weld. In the IIW guideline [1], this stress magnification is captured for flat plates applying an analytical expression derived in [2]. A thorough investigation focussing on the detailed effects of weld location in the plate, its length over width ratio and load magnitude by the use of analytical approaches is published in [3]. Further studies incorporating finite element simulation runs focus on more complex assemblies such as panel structures in ships or girth welds for pipelines $[4,5]$.

In literature, only a limited amount of fatigue test results for butt-welds with emphasis on the effect of axial misalignment is available, see [6-8]. In [9], a summary of fatigue test results for steels is presented considering the correction factors for misalignment as suggested in [2]. Thereby, for a number of load cycles above $10^{4}$, the resulting S-N curve shows a rather good accordance with limited scatter. The same authors published investigations on the influence of the offset to sheet thickness ratio of butt joints in [10], clearly showing the detrimental effect of the axial misalignment. For cruciform welded joints, selected fatigue test results are listed in [11-14]. 
The aim of this work is to investigate the effect of axial misalignment for ultra high-strength steel butt joints on the fatigue performance. Furthermore, common stress-based methods will be applied to assess different levels of axial misalignment. Finally, equations for stress magnification factors considering these geometric butt joint deviations are obtained.

\section{Fatigue test samples}

The experimental part of this work covers fatigue testing of butt-welded specimens exhibiting different axial misalignment values $e$; the corresponding specimen geometry is shown in Fig. 1. Thereby, crack initiation should occur at the weld toe on the upper side of the specimen. The aim of the manufacturing process is to establish three levels of axial misalignment:

- V0: no axial misalignment, $e=0 \mathrm{~mm}, e / t=0$

- V1: moderate axial misalignment, $e=0.75 \mathrm{~mm}, e / t=$ 0.125

- V2: high axial misalignment, $e=1.5 \mathrm{~mm}, e / t=0.25$

According to limitations for axial misalignment given in the standard EN ISO 5817 [15], the first grade V0 without any offset represents quality level B, whereas the second V1 lies in level $\mathrm{C}$ and the third offset V2 represents the maximum allowable quality level D.

\subsection{Specimen manufacturing}

The full-penetrating butt joint is welded as two-layered MAG welded V seam using S1100 base material with $t=6 \mathrm{~mm}$ sheet thickness, G89 solid wire filler metal and standard M21 shielding gas. Table 1 summarises the mechanical properties of base and filler metal. The parameters for the semiautomated welding process are adjusted to ensure a fully penetrated weld and a cooling rate within the recommendations of the steel manufacturer with a $t_{8 / 5}$ time of 5 to $20 \mathrm{~s}$. Thereby, sheets with a length of $500 \mathrm{~mm}$ are welded at once. In order to achieve the desired levels of axial misalignment, an additional sheet with the corresponding thickness is put underneath one side of the base material sheets during welding. After waterjet cutting of the specimens from the sheet, the weld root is ground flush to plate to prevent crack initiation from this region. This leads to a slanting transition zone due to the offset between the sheets. In the case of the highly misalignment specimens, it is not possible to establish a fully smooth transition area leading to a remaining root notch. Therefore, HFMI post-treatment is applied to this region at the weld root to avoid unfavourable crack initiation in this area. Furthermore, the sheet edges are mechanically treated to prevent crack initiation from the edges. Figure 2 shows the three specimen types side by side; the axial misalignment decreases from front to back. The overview of the specimens' bottom surfaces in Fig. $2 \mathrm{~b}$ clearly marks HFMI-treated area of the specimen with high axial misalignment as well as the transition zone of the specimen with moderate offset.

Figure 3 shows the microsection of each misalignment grade. The measures of the two-layered weld are quite equal for all investigated microsections, although differences especially at the weld toe are visible. Furthermore, in (b) and (c), the actual shape of the transition zone around the weld root can be observed. Whereas it is smooth in the case of the moderate offset specimen including a significant reduction in plate thickness, the HFMI-treated part of the weld root is clearly visible in case of the specimen with high offset without any reduction in plate thickness.

For the investigation of the effect of HFMI treatment on axially misaligned specimens, 30 specimens of offset-free butt joints and eight samples per misalignment grade V1 and V2 were additionally post-weld treated at the weld toes. Hereby, a pin-radius of $2 \mathrm{~mm}$ and a frequency of $90 \mathrm{~Hz}$ is used. Figure 4 shows a microsection of the weld topography of an HFMItreated specimen without axial misalignment. The measurement of the actual weld toe radius after post-weld treatment reveals values of about 2.5 up to $4 \mathrm{~mm}$.

Fig. 1 Specimen geometry

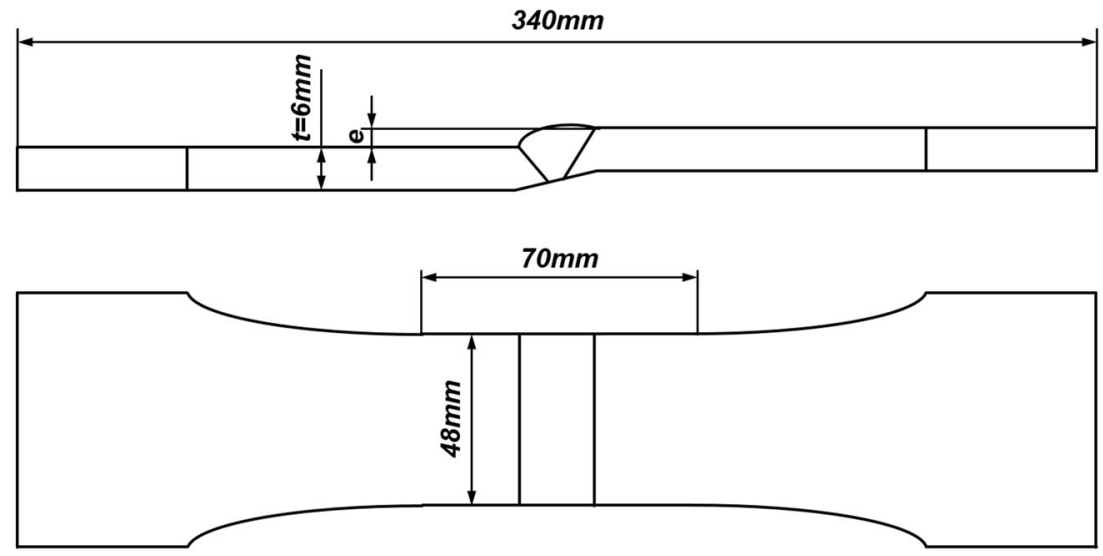


Table 1 Mechanical properties of base and filler material

\begin{tabular}{lllll}
\hline Material & Yield strength & $\begin{array}{l}\text { Tensile strength } \\
\sigma_{\mathrm{u}}(\mathrm{MPa})\end{array}$ & $\begin{array}{l}\text { Elongation } \\
A(\%)\end{array}$ & Impact work ISO-V $K V(\mathrm{~J})$ \\
& $\sigma_{\mathrm{y}}(\mathrm{MPa})$ & $\geq 1140$ & $\geq 8$ & \\
\hline Base, S1100 & $\geq 1100$ & $\geq 940$ & $\geq 16$ & $\geq 27$ @ $-20^{\circ} \mathrm{C}$ \\
Filler, G89 & $\geq 890$ & $-60{ }^{\circ} \mathrm{C}$ \\
\hline
\end{tabular}

\subsection{Measurement of actual specimen misalignment}

An accurate determination of the specimen distortion is a key issue when investigating its effect on the fatigue strength. Therefore, every sample undergoes misalignment measurements mainly following the procedure suggested in [16]. As depicted in Fig. 5, the specimen is fixed on one end and the deformation is measured at six points at the weld root side of the specimen by the aid of a dial gauge. Thereby, all measuring points lie outside the ground area at the weld root. Subsequently, linear regression over three points per side is performed to estimate the sheet surface curvature enabling the calculation of welding distortion angle $\alpha$ and the axial misalignment $e$ at the centre of the weld.

Table 2 lists the results of the distortion measurements. The mean values of the actual axial misalignment are roughly at the desired level. For the moderate misalignment grade V1, it is slightly lower than the intended value, though. The scatter band within each series is about the same for all three misalignment grades. The angular distortion shows positive values based on the definition in Fig. 5a. According to EN ISO 5817 [15], all specimens are within the highest quality level $\mathrm{B}$ allowing angular misalignment values up to $1^{\circ}$. Based on the results shown in this table, HFMI treatment shifts the welding distortion in negative direction and increases its standard deviation. A similar tendency was observed within a previous work on angular distortion in [17].

\section{Fatigue tests}

Two test rigs are utilised for load controlled cyclic testing upon the desired load level. A hydropulse test rig allowing test frequencies up to $12 \mathrm{~Hz}$ is utilised for the finite life domain where specimen failure is expected. On the other hand, a resonator enabling frequencies up to $90 \mathrm{~Hz}$ is employed for specimens near or at the run-out level increasing the testing speed significantly. The tests are performed until burst fracture of the specimen or its run-out at a level of ten million load cycles for as-welded specimens without misalignment, series V0, and five million otherwise. For statistical analysis of the fatigue test results, ASTM E739 [18] is applied; for estimation of the fatigue strength at run-out level, arcsinsqrt P-method according to [19] is exercised. Beyond the transition knee point, a declination of $10 \%$ per decade is considered corresponding to an inverse slope value of $k^{\prime}=22$. This matches the recommendation for constant amplitude loading given in [20]. For fatigue tests with specimens exhibiting axial misalignment, it is important to compensate this offset by the use of compensation plates as shown in Fig. 6. Otherwise, clamping of the specimen would lead to an additional "S-" shaped bending of the specimen, which basically does not represent the desired geometry shape conditions. The angular distortion is not counteracted within the fatigue tests, as the absolute values are small and comparable for all specimens. Since the free specimen length between the clamping jaws plays a role within the local stiffness and therefore affects deformation around the weld, it is set to a constant value of $200 \mathrm{~mm}$ at both test rigs.

At this point, it should be noted that the actual cross section at the weld toe is used as basis for calculation of the load to achieve the desired nominal stress level. Therefore, the sheet thickness is measured near the weld toe exhibiting the lowest cross section (see Fig. $3 \mathrm{~b}$ and c). This has a considerable influence especially for the specimen exhibiting moderate misalignment due to the grinding process of the weld root significantly reducing sheet thickness on the 'critical' side of the weld. The average sheet thickness in this critical region for all tested specimens of series V1 is $t=5.83 \mathrm{~mm}$.
Fig. 2 a and b Overview of specimens with high (front), moderate and no axial misalignment (back)

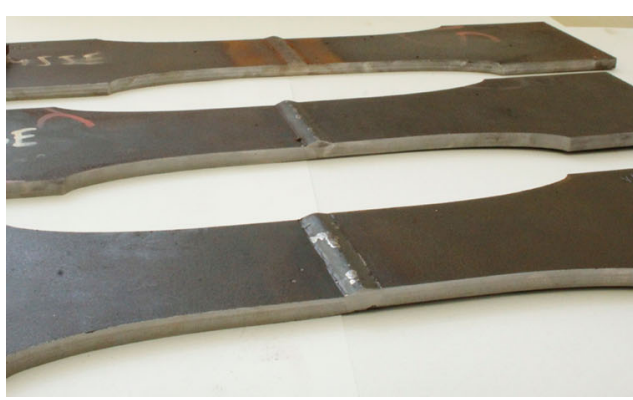

(a) Weld reinforcement topography

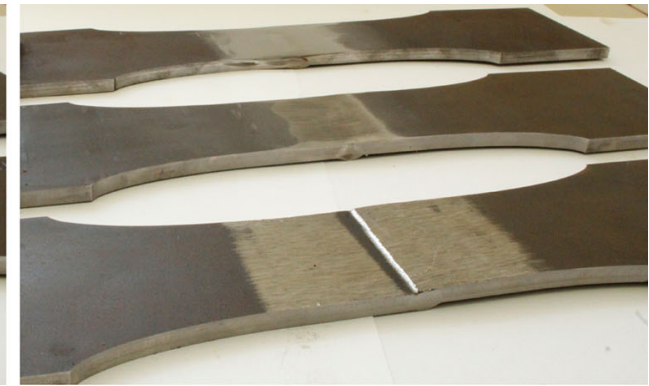

(b) Weld root topography 
Fig. 3 a-c Microsections of the investigated specimen types

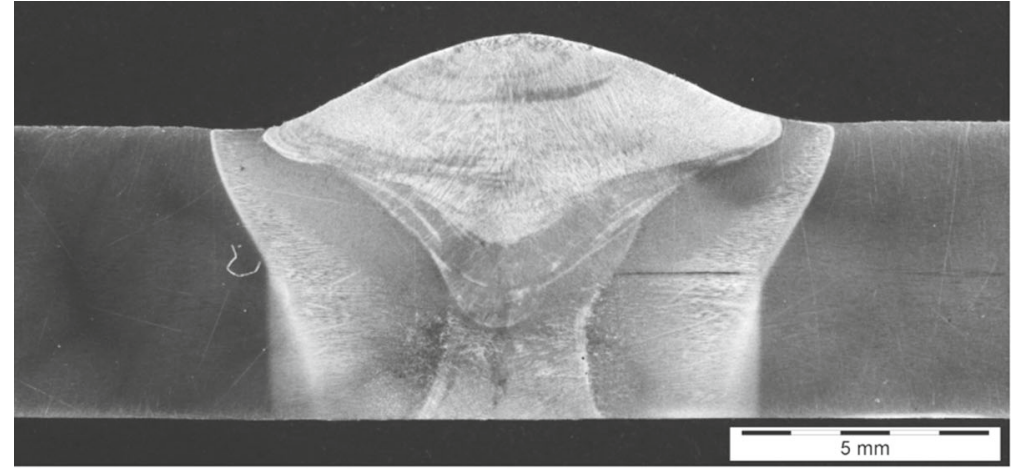

(a) Specimen series V0 without axial misalignment, $e / t=0$

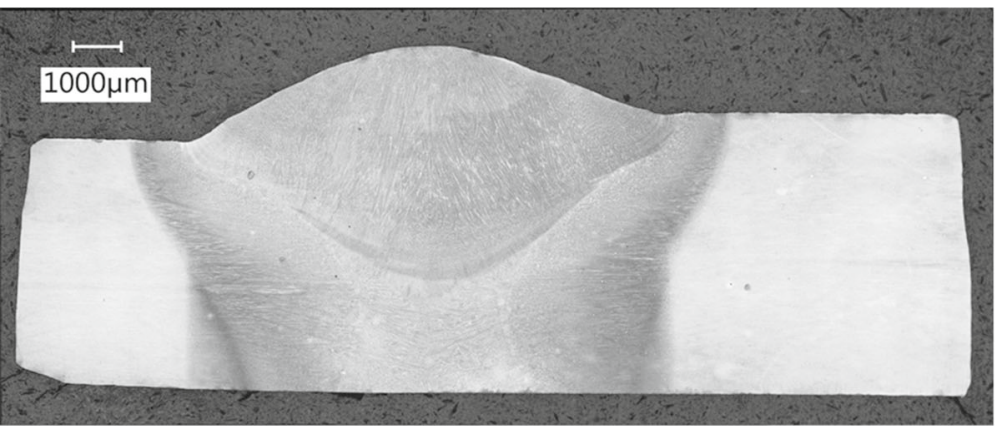

(b) Specimen series $\mathrm{V} 1$ exhibiting approximately $0.75 \mathrm{~mm}$ axial misalignment, $e / t=0.125$

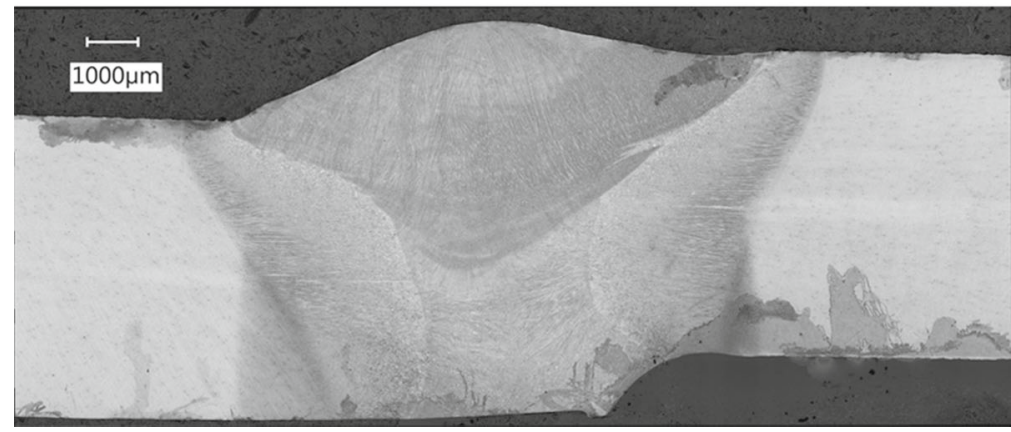

(c) Specimen series V2 exhibiting approximately $1.5 \mathrm{~mm}$ axial misalignment, $e / t=0.25$
Figure 7 shows the fatigue test results for as-welded state in terms of nominal stresses. The corresponding data is listed in Table 3. The recommended FAT values according to [1] are included in the graph for every offset level. The present butt joints are classified as FAT80 due to a weld reinforcement height exceeding $10 \%$ of sheet thickness. Considering the effective sheet thickness of $t_{\text {eff }}=6 \mathrm{~mm}$, the FAT value is upgraded to FAT106. For the misaligned joints, the FAT value is adjusted to FAT89 for moderate and FAT66 for high offset values. Further details are given in Section 5.1. Specimens with moderate offset still meet the recommended FAT106 for offset-free specimen whereas the results for high offset are below this limit. The increasing sheet offset leads to a significantly lower fatigue resistance in finite life domain as well as run-out level. This goes along with an increase of scatter index from 1: $T_{\sigma}=1.18$ for offset-free specimen to 1.35 for an offset of $e=1.5 \mathrm{~mm}$ and a reduction in natural inverse slope from $k=4.8$ to 4.3 . The specimen misalignment additionally causes a shift of the knee point $N_{\mathrm{k}}$ towards higher numbers of load cycles. None of the 16 broken specimens without misalignment failed above one million load cycles. In the case of misaligned specimens, two of $12 \mathrm{~V} 1-$ and two

Fig. 4 Microsection of HFMI post-weld treated specimen without misalignment

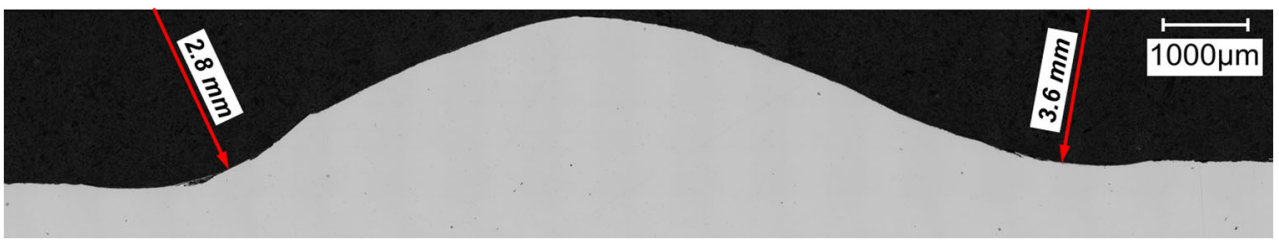




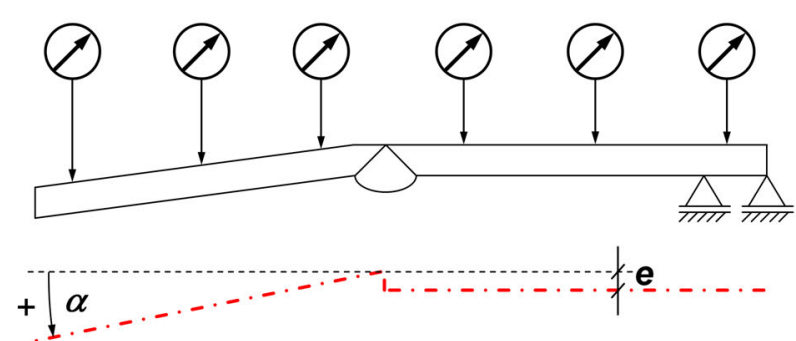

(a) Principle of misalignment measurement

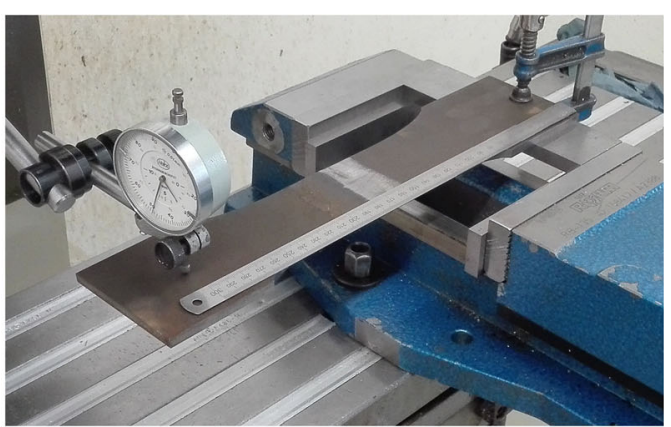

(b) Measurement setup

Fig. 5 a and b Measurement of specimen misalignment

of ten V2-specimen showed failure above this limit. In [21], the results of fatigue tests of mild and high-strength steel fillet welds in tension and pure bending loading show a noticeable shift of the S-N curves knee point towards higher load cycle numbers in case of bending load. Therefore, the observed behaviour could possibly be traced back to the increasing portion of secondary bending loading caused by the weld offset. In the case of as-welded specimen, failure exclusively occurs at the weld toe. Considering the misaligned series, the point of crack initiation lies always at the weld toe of the lower sheet due to a higher stress concentration; see Section 4.

\section{Numerical analysis}

The investigations regarding to local stress distribution of the studied specimens are performed by a linear elastic numerical simulation. For this purpose, three 3D-solid models exhibiting axial misalignments of $0 \mathrm{~mm}, 0.75 \mathrm{~mm}$ and $1.5 \mathrm{~mm}$ are set up using a geometry based on the weld topology of the microsections in Fig. 3. The models exhibit a distance between the weld toes of $11 \mathrm{~mm}$ and a circular weld reinforcement height of $2 \mathrm{~mm}$ measured from the 'lower' sheet surface; see Fig. 8a. As the actual weld geometry is not fully circular, this produces slightly higher weld reinforcement angles in case of the simulation model. Based on the results of numerical investigations on the effect of weld reinforcement height and angle on the stress concentration factors of welds in [22], this might lead to slightly elevated results. The ground weld root is modelled as linear transition over a distance of $5 \mathrm{~mm}$. Both, the weld toe as well as the notch at the root are rounded with a fictitious reference radius of $r_{\text {ref }}=1 \mathrm{~mm}$ according to the effective notch stress concept for welded joints [23-25]. The meshing of the half-symmetrical model is performed in accordance with the suggestions in [26] with a tangential edge length at about $0.08 \mathrm{~mm}$ at rounded notches and an aspect ratio of 2:1 in depth by the use of second-order elements with reduced integration, see Fig. 8b. Linear elastic material parameters for steel are applied with an elastic modulus of $E=$ $210,000 \mathrm{MPa}$ and a Poisson's ratio of $\nu=0.3$.

The clamping is modelled to comply with the testing facilities for the conducted fatigue tests using rigid clamping. This method assumes a very high stiffness of the rest rig compared with the specimen, otherwise the influence of the specimens secondary bending is not assessed properly. In [27], a holistic study on the effect of secondary bending including a strain gauge measurements and subsequent comparison to numerical results was performed using specimens of similar stiffness and the same testing facilities. The investigations show the use of rigid clamping is sufficient for the present test rig and

Table 2 Results of distortion measurements

\begin{tabular}{|c|c|c|c|c|c|c|c|}
\hline \multirow[t]{2}{*}{ Misalignment level } & \multirow{2}{*}{$\begin{array}{l}\text { Intended axial } \\
\text { misalignment (mm) }\end{array}$} & \multirow{2}{*}{$\begin{array}{l}\text { Weld toe } \\
\text { condition }\end{array}$} & \multirow{2}{*}{$\begin{array}{l}\text { Number of } \\
\text { measured specimens }\end{array}$} & \multicolumn{2}{|c|}{ Axial misalignment (mm) } & \multicolumn{2}{|c|}{ Angular misalignment $\left({ }^{\circ}\right)$} \\
\hline & & & & Average & $\begin{array}{l}\text { Standard } \\
\text { deviation }\end{array}$ & Average & $\begin{array}{l}\text { Standard } \\
\text { deviation }\end{array}$ \\
\hline V0 & 0 & As-welded & 32 & 0.17 & 0.12 & 0.29 & 0.19 \\
\hline V1 & 0.75 & As-welded & 29 & 0.65 & 0.18 & 0.56 & 0.28 \\
\hline V2 & 1.5 & As-welded & 27 & 1.51 & 0.15 & 0.29 & 0.20 \\
\hline V0 & 0 & HFMI-treated & 30 & 0.25 & 0.21 & 0.20 & 0.23 \\
\hline V1 & 0.75 & HFMI-treated & 8 & 0.65 & 0.32 & -0.05 & 0.41 \\
\hline $\mathrm{V} 2$ & 1.5 & HFMI-treated & 8 & 1.53 & 0.2 & 0.09 & 0.36 \\
\hline
\end{tabular}




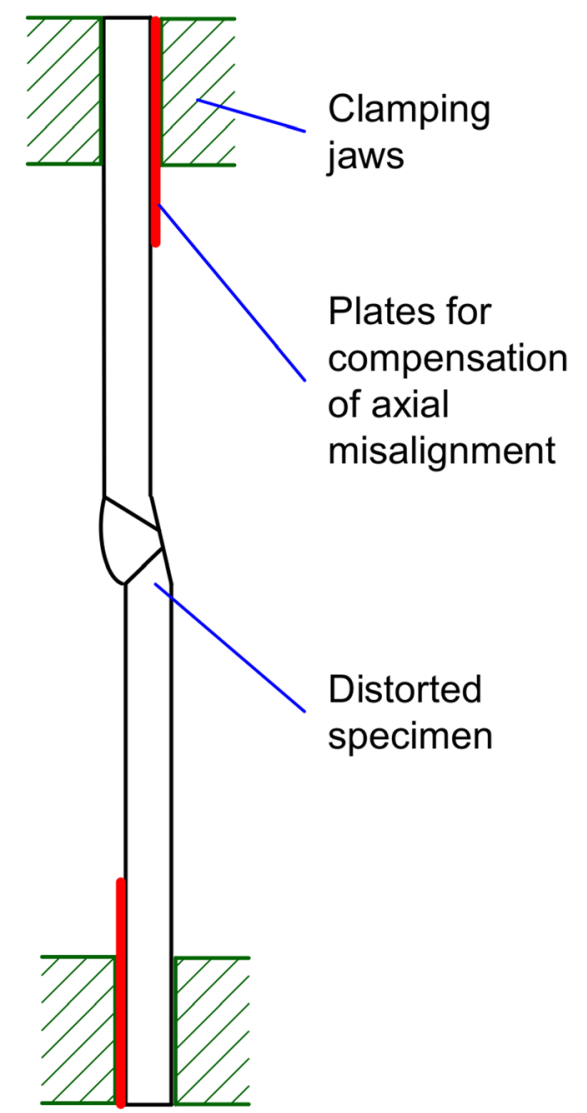

Fig. 6 Compensation of axial misalignment during fatigue testing

specimen combination. Therefore, the sheet surface at the clamping jaws is fully clamped including rotational degrees of freedom, only movement in load direction is allowed on one side. At first, a unity load leading to a nominal stress of $1 \mathrm{MPa}$ is applied in order to assess the stress concentration factors. Subsequently, the nominal load is increased to $1000 \mathrm{MPa}$ to study the effect of very high loads. For a proper assessment of these nonlinear geometric effects due to high deformations properly, the large deformation theory has to be enabled.

Figure 9 shows the analysis results for unity load of the three investigated models in terms of absolute maximum principal stresses. Here, the rise in stress concentration with increasing misalignment level is clearly visible. In the case of the misaligned specimens, the maximum of the stress distribution is located at the weld toe of the lower side of the weld. Furthermore, the stress distributions reveal the increasing amount of bending due to the misalignment. The simplified model of the weld root points out another stress concentration in this region emphasising the need and application of HFMI treatment in this area to prevent unfavourable crack initiation. The hot-spot stress concentration factor $K_{\mathrm{hs}}$ according to IIW [1, 28, 29] are evaluated using linear extrapolation formulae, see Eq. 1.

$\sigma_{\text {hs }}=1.67 \sigma_{0.4 t}-0.67 \sigma_{1.0 t}$

The structural and the effective notch stress concentration factors $K_{\mathrm{t}}$ at the weld toe and ground weld root are listed in Table 4. In this context, Fig. 10 provides an overview of the stress definitions and the corresponding evaluation procedure. Furthermore, the hot-spot and effective notch stresses for a nominal load of $1000 \mathrm{MPa}$ are listed in this table. This high
Fig. 7 Fatigue test results for aswelded specimen

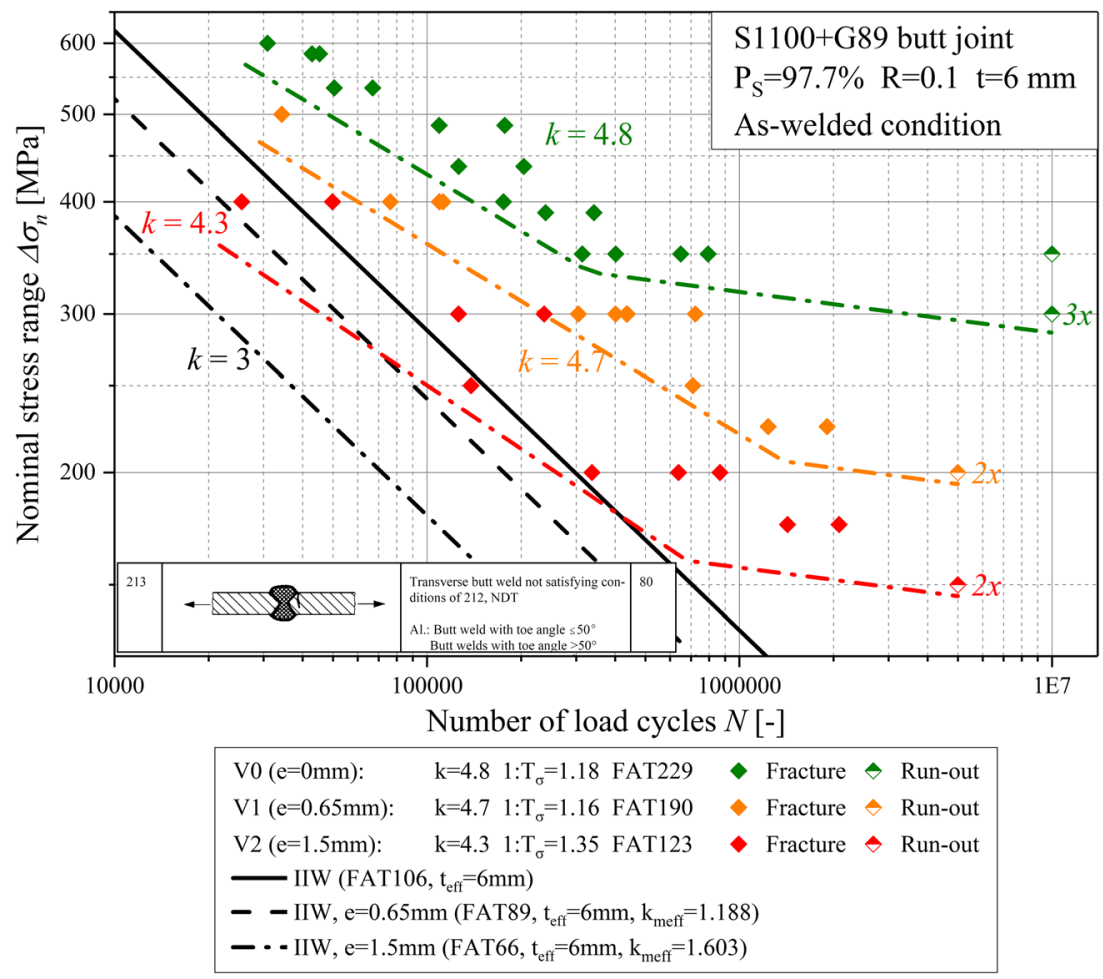


Table 3 Summary of fatigue test results in as-welded condition

\begin{tabular}{|c|c|c|c|c|c|c|c|c|}
\hline \multirow[t]{2}{*}{$\begin{array}{l}\text { Misalignment } \\
\text { level }\end{array}$} & \multirow[t]{2}{*}{$\begin{array}{l}\text { Weld toe } \\
\text { treatment }\end{array}$} & \multirow{2}{*}{$\begin{array}{l}\text { Inverse } \\
\text { slope } k \\
(-)\end{array}$} & \multirow{2}{*}{$\begin{array}{l}\text { Scatter } \\
\text { index } \\
1: T_{\sigma}(-)\end{array}$} & \multirow{2}{*}{$\begin{array}{l}\text { Transition knee } \\
\text { point } N_{\mathrm{k}}(-) \\
\left(P_{\mathrm{S}}=97.7 \%\right)\end{array}$} & \multicolumn{2}{|c|}{ FAT value } & \multicolumn{2}{|c|}{$\begin{array}{l}\Delta \sigma_{\text {run-out }} \\
\left(P_{\mathrm{S}}=97.7 \%\right)\end{array}$} \\
\hline & & & & & $(\mathrm{MPa})$ & $(\%)$ & (MPa) & $(\%)$ \\
\hline V0 & As-welded & 4.8 & 1.18 & 315,000 & 229 & 100 & 288 & 100 \\
\hline V1 & As-welded & 4.7 & 1.16 & $1,390,000$ & 191 & 83 & 194 & 67 \\
\hline $\mathrm{V} 2$ & As-welded & 4.3 & 1.35 & 680,000 & 123 & 54 & 146 & 51 \\
\hline
\end{tabular}

load leads to small but noticeable deviations from the nominal linear stress concentration values due to nonlinear effects. However, the maximum deviation compared to linear stress concentration is lower than $4 \%$ and the actual maximum load during the fatigue tests lies at just about $780 \mathrm{MPa}$. Therefore, the correlation between load and stress concentration is assumed linear.

The subsequent fatigue assessment procedure requires a detailed calculation of the stress concentration factors for every misalignment state. A regression of the values in Table 4 reveals a linear correlation of the stress concentration factors with increasing misalignment level $e$ summarised in the following Eq. 2 and Eq. 3:

$$
\begin{aligned}
& K_{\mathrm{hs}}(e)=1.025+0.46224 \frac{1}{\mathrm{~mm}} \cdot e \\
& K_{\mathrm{t}}(e)=1.708+0.79817 \frac{1}{\mathrm{~mm}} \cdot e
\end{aligned}
$$

\section{Fatigue assessment of as-welded specimen}

This section deals with an assessment of the effect of axial misalignment on the fatigue strength of welded ultra highstrength steel butt joints in as-welded condition. Thereby, commonly applied stress-based fatigue assessment methods as suggested in [1] are applied.

\subsection{Nominal stress approach}

The IIW guideline [1] utilises the stress magnification factor $k_{\mathrm{m}}$ for nominal and structural stress approaches in order to take misalignments into account. Either the applied stress could be multiplied by $k_{\mathrm{m}}$ or the respective fatigue resistance is divided by $k_{\mathrm{m}}$ to consider the misalignment within the design process. In the case of butt-welded flat sheets, only axial and angular misalignment can occur, either just one or in combination. As the angular misalignments measured at the present investigated specimens are rather small and comparable, they are subsequently neglected. Figure 11 sketches a welded joint exhibiting axial misalignment, whereas Eq. 4 gives the according mathematical context.

$k_{\mathrm{m}, \text { axial }}=1+\lambda \frac{\mathrm{e} \cdot \mathrm{l}_{1}}{\mathrm{t} \cdot\left(\mathrm{l}_{1}+\mathrm{l}_{2}\right)}$

Thereby, the parameter $\lambda$ stands for a factor dependent on the restraint of the specimen. This equation is initially derived for cruciform and butt joints in [2]. In the case of cruciform joints, restraining of the stiffeners allows several levels of restraint. For butt joints, on the other hand, only two boundary

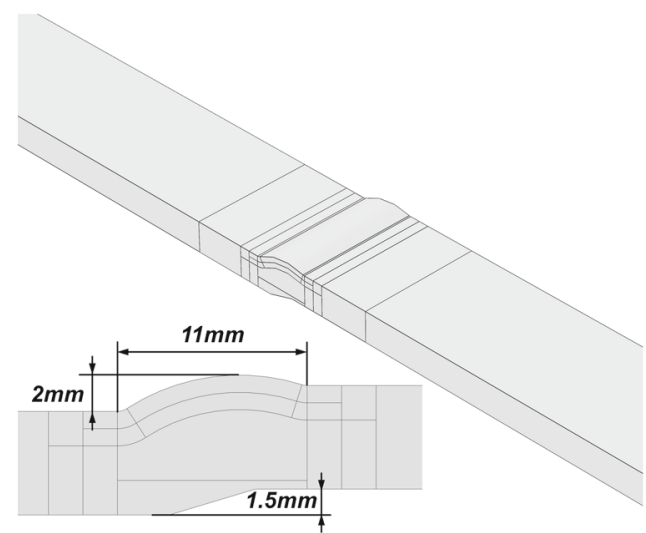

(a) Model geometry for high axial misalignment

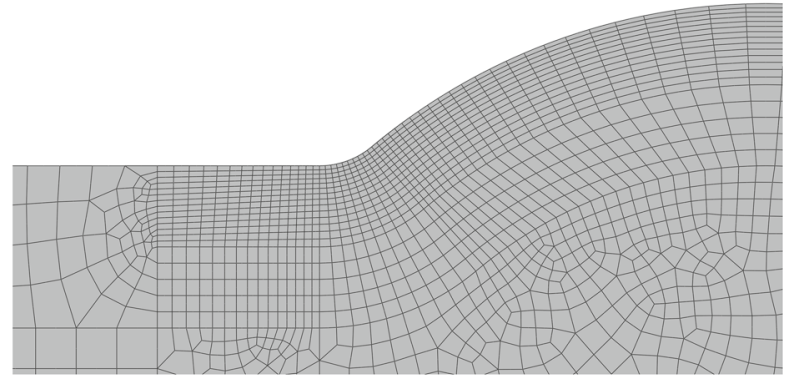

(b) Meshing at the weld toe

Fig. 8 a and $\mathbf{b}$ Model setup for numerical analysis 


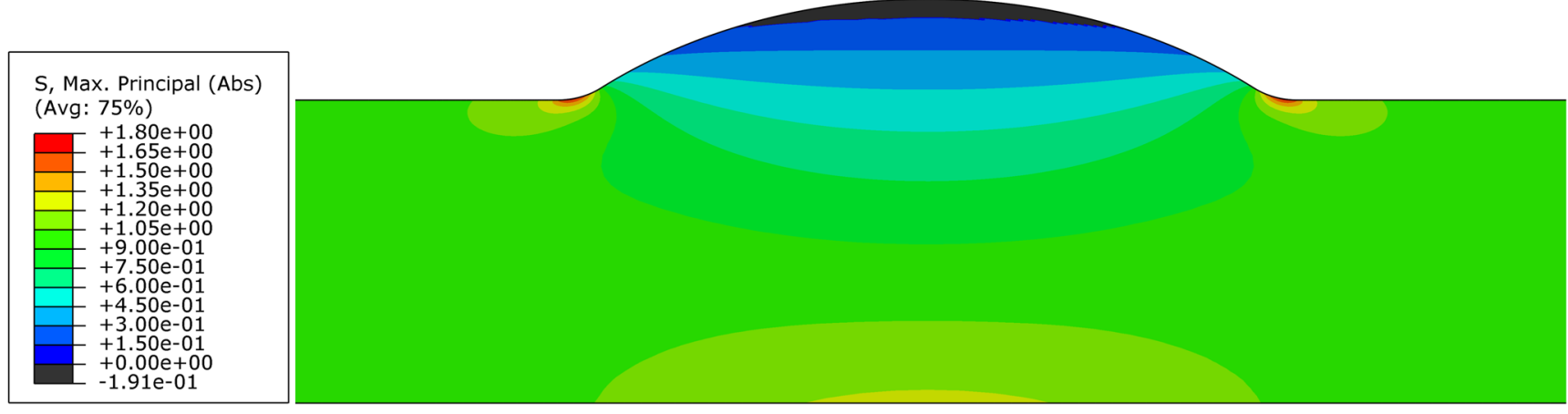

(a) V0, no axial misalignment
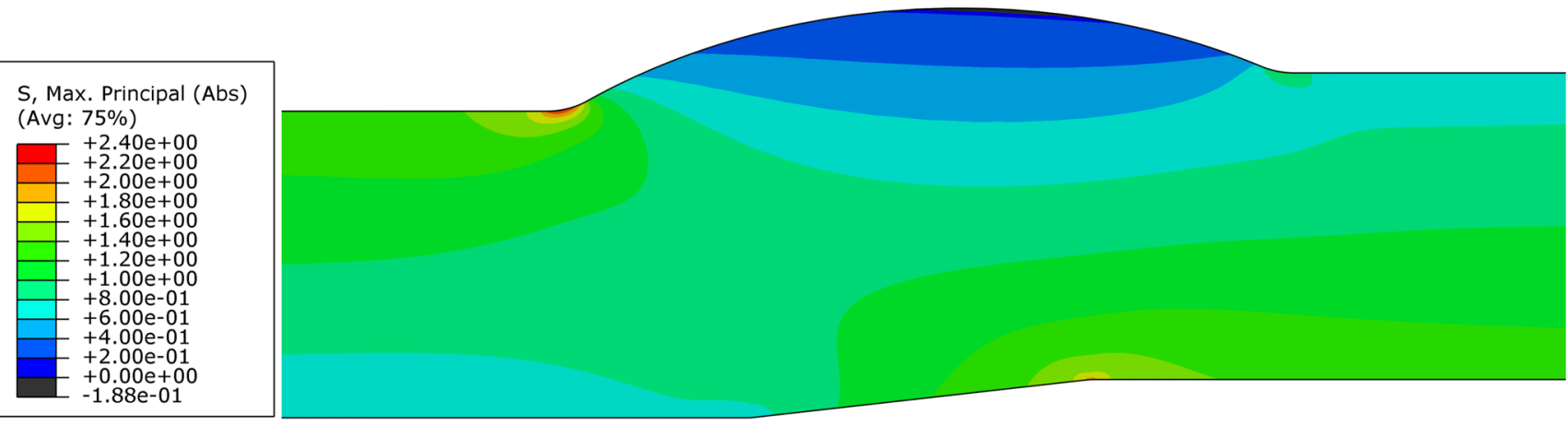

(b) V1, moderate axial misalignment
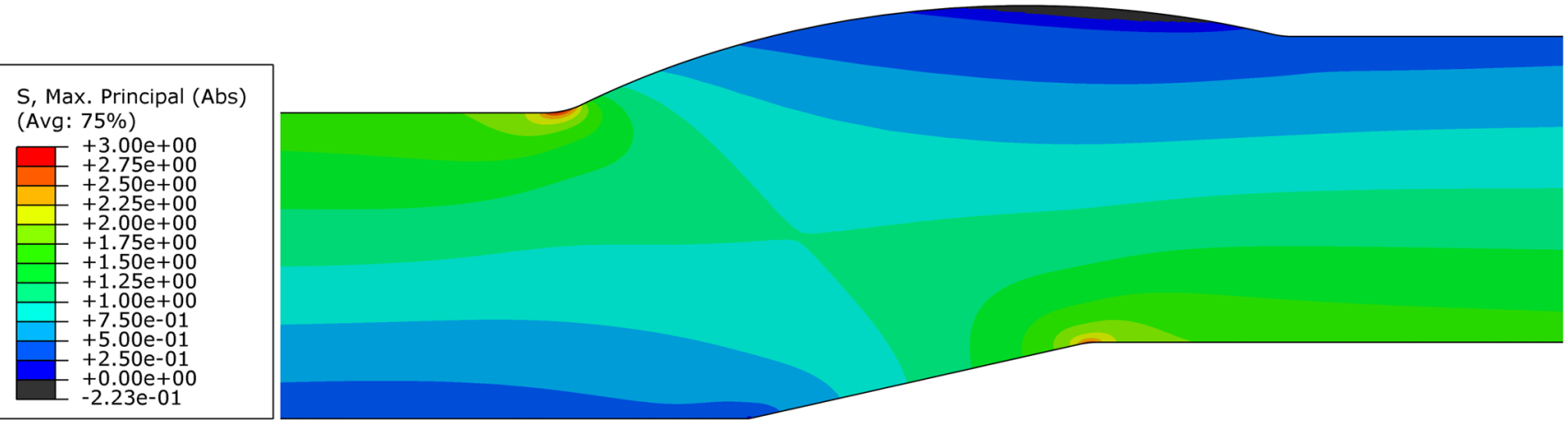

(c) V2, high axial misalignment

Fig. 9 a-c Results of numerical analysis in terms of absolute maximum principal stress at the weld

Table 4 Stress concentration factors for various misalignment values derived from numerical analysis

\begin{tabular}{|c|c|c|c|c|c|}
\hline \multirow[t]{2}{*}{ Axial misalignment $e(\mathrm{~mm})$} & \multicolumn{3}{|c|}{ Unity load $\left(\sigma_{\mathrm{N}}=1 \mathrm{MPa}\right)$} & \multicolumn{2}{|l|}{$\sigma_{\mathrm{N}}=1000 \mathrm{MPa}$} \\
\hline & $\begin{array}{l}K_{\mathrm{hs}}(-) \\
\text { (weld toe) }\end{array}$ & $\begin{array}{l}K_{\mathrm{t}}(-) \\
\text { (weld toe) }\end{array}$ & $\begin{array}{l}K_{\mathrm{t}}(-) \text { (ground } \\
\text { weld root) }\end{array}$ & $\begin{array}{l}\text { Hot-spot stress } \\
\sigma_{\mathrm{hs}}(\mathrm{MPa}) \\
\text { (weld toe) }\end{array}$ & $\begin{array}{l}\text { Effective notch stress } \\
\sigma_{\text {notch }}(\mathrm{MPa}) \\
\text { (weld toe) }\end{array}$ \\
\hline 0 & 1.025 & 1.708 & - & 1061.3 & 1771.3 \\
\hline 0.75 & 1.371 & 2.327 & 1.978 & 1360.0 & 2319.3 \\
\hline 1.5 & 1.719 & 2.895 & 2.717 & 1660.6 & 2816.9 \\
\hline
\end{tabular}


Fig. 10 Definition of stresses and stress concentrations

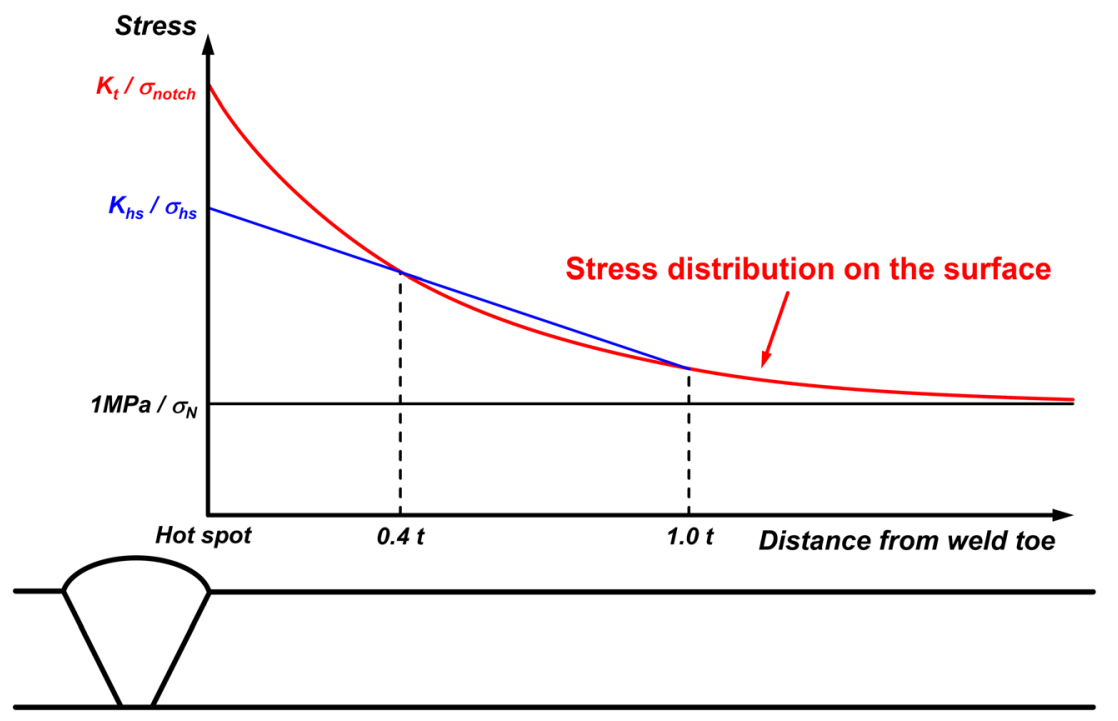

conditions are feasible which are related to the clamping situation of the specimen. If the clamping allows a rotational degree of freedom, $\lambda=6$ is applied, if not, then $\lambda=6.75$. As the test rig does not allow any rotation and its stiffness is far higher compared with the specimen, the latter value applies for the present case. The weld of the investigated specimens is in the middle between the clamping jaws leading to $l_{1}=l_{2}=$ $\mathrm{L} / 2$. Therefore, the stress magnification factor is according to this analytical expression not dependent on the length of the specimen.

The recommended nominal stress FAT classes already cover a certain amount of misalignment corresponding to a stress magnification factor of $k_{\mathrm{m}}=1.15$ for butt joints made in workshop in flat position. This value is for the present case $(\lambda=6.75, t=6 \mathrm{~mm})$ equivalent to an axial misalignment of $e=0.267 \mathrm{~mm}$. Thus, only stress magnifications exceeding this value need to be considered additionally. If so, an effective stress magnification factor is introduced, see Eq. 5:

$k_{\mathrm{m}, \mathrm{eff}}=\frac{k_{\mathrm{m}, \text { calculated }}}{k_{\mathrm{m}, \text { already covered }}}$

Table 5 lists the actual and the effective stress magnification factors for various axial misalignments; for improved comparability, the respective values acquired using FEsimulation are shown as well. Furthermore, the table shows the values for $k_{\mathrm{m}, \mathrm{hs}}$ and $k_{\mathrm{m}, \mathrm{t}}$ resulting from the division of the respective stress concentration $K$ by the stress concentration

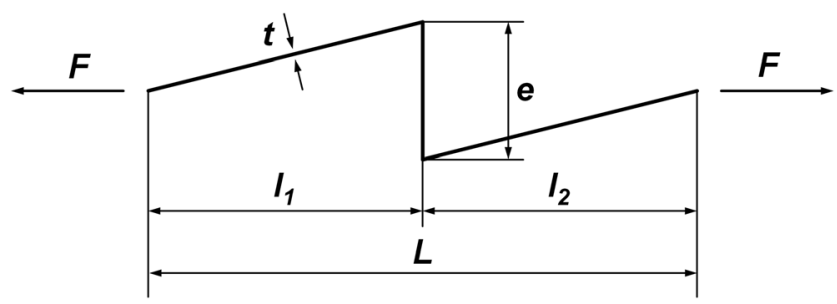

Fig. 11 Axial misalignment of flat sheets $[1,9]$ without axial misalignment. The values comply rather with the $k_{\mathrm{m}}$ values of $\lambda=6$ than to $\lambda=6.75$, which would actually apply to the test setup. A reason for this can be found in the flexibility of the thin-walled specimens and the comparably large distance $\mathrm{L}$ of over 33 times the sheet thickness. This might lead to a fictitious rotational degree of freedom for the local weld detail yielding to $\lambda=6$ giving more suitable results. However, for further evaluation $\lambda=6.75$ is applied as it is the suggested value.

Based on these effective stress magnification factors, the recommended FAT class for butt joints considering the effective sheet thickness FAT106 is adjusted to FAT89 for moderate and FAT66 for high offset values. The result is plotted in Fig. 7. All fatigue tests for axial misalignment level V1 are above FAT106; therefore, further adjustment would not have been required. But for specimens V2 exhibiting high offset values, the use of $k_{\mathrm{m} \text {,eff }}$ is necessary in order to assess the axial misalignment properly.

Furthermore, the assessed $k_{\mathrm{m}}$ values are utilised to correlate the fatigue test results of different misalignments. Every fatigue test result is multiplied with the $k_{\mathrm{m}}$ value according to the axial misalignment of the respective specimen using Eq. 4. For these calculations, the parameter $\lambda$ is set to a value of $\lambda=6.75$ as suggested in [2]. The result in Fig. 12(a) shows a distinct reduction of scatter for the whole S-N curve. Table 6 lists the related values of the statistical evaluation. In the finite life domain, the individual misalignment fatigue design lines implying a probability of survival of $P_{S}=97.7 \%$ as well as the combined evaluation are in sound accordance. However, the shift of the mean $P_{S}=50 \%$-lines to higher load cycle numbers with increasing offset indicates a slight overestimation of the stress magnification. In the high-cycle fatigue region, on the other hand, a comparably high deviation between the fatigue test results incorporating offset-free and axially misaligned specimens is observed. The individual shift of 
Table 5 Stress magnification and stress concentration factors

\begin{tabular}{|c|c|c|c|c|c|c|c|}
\hline \multirow{2}{*}{$\begin{array}{l}\text { Axial } \\
\text { misalignment } e \\
(\mathrm{~mm})\end{array}$} & \multirow{2}{*}{$\begin{array}{l}k_{\mathrm{m} \text {,axial }}[-] \\
\lambda=6\end{array}$} & \multirow{2}{*}{$\begin{array}{l}k_{\mathrm{m} \text {,axial }}[-] \\
\lambda=6.75\end{array}$} & \multirow{2}{*}{$\begin{array}{l}k_{\mathrm{m}, \mathrm{eff}}[-] \\
\lambda=6.75\end{array}$} & \multicolumn{4}{|c|}{ Numerical analysis } \\
\hline & & & & $\begin{array}{l}K_{\mathrm{hs}}[-] \\
\text { (weld toe) }\end{array}$ & $k_{\mathrm{m}, \mathrm{hs}}[-]$ & $\begin{array}{l}K_{\mathrm{t}}[-] \\
\text { (weld toe) }\end{array}$ & $k_{\mathrm{m}, \mathrm{t}}[-]$ \\
\hline 0 & 1 & 1 & 1 & 1.025 & 1 & 1.708 & 1 \\
\hline 0.65 & 1.325 & 1.366 & 1.188 & $1.324 *$ & 1.292 & $2.244 *$ & 1.314 \\
\hline 0.75 & 1.375 & 1.421 & 1.236 & 1.371 & 1.338 & 2.327 & 1.362 \\
\hline 1.5 & 1.750 & 1.844 & 1.603 & 1.719 & 1.677 & 2.895 & 1.695 \\
\hline
\end{tabular}

*Calculated using linear interpolation

fatigue test result points does not allow a proper arcsinsqrt $\mathrm{P}$-evaluation for axial misalignment levels V1 and V2. Therefore, in the high-cycle fatigue domain, no statistical evaluation is performed.

\subsection{Structural stress approach}

Fatigue assessment using structural hot-spot stresses [29] applies basically the same stress magnification factors $k_{\mathrm{m}}$ as nominal stress approaches. However, assessment is also possible using the results of numerical studies. Both, the analytical $k_{\mathrm{m}}$ and the numerically determined values $K_{h s}$ are listed in Table 5. According to these results, a restraint factor $\lambda=6$ is more consistent with the numerical results than $\lambda=6.75$. As already stated, this could be traced back to a comparably high $\mathrm{L} / \mathrm{t}$-ratio of the specimens reducing the restraint noticeably. Based on these findings, the length between the clamps does influence the stress magnification of the joint in terms of secondary bending in contrast to the analytical expression.

The calculation of every fatigue test results' structural stress is performed using Eq. 2, the individual specimen misalignment value $e$ and the respective nominal stress range. Figure $12 \mathrm{~b}$ shows the consequential $\mathrm{S}-\mathrm{N}$ curve in terms of structural stress range, the related values of the statistical evaluation are listed in Table 6. This evaluation method leads to a reduced scatter band for all three individual misalignment levels as well as the combined evaluation in comparison to the nominal stress approach in Section 5.1. Furthermore, the mean $P_{S}=50 \%$-lines are almost congruent in the finite life domain showing a sound estimation of the notch effect in this region. However, the structural stress approach is not suitable to describe the shift of the knee point $N_{k}$ to a higher number of load cycles with increasing offset. Thus, a proper assessment of the high-cycle fatigue regime is not feasible with this approach.

\subsection{Effective notch stress approach}

The assessment of the fatigue test results on the basis of the effective notch stress approach is performed by the aid of the stress concentration factor analysis of each specimen type using a reference radius of $r_{\text {ref }}=1 \mathrm{~mm}$, see Section 4. Therefore, each data point acquired during the fatigue tests is multiplied by the respective stress concentration factor determined by the use of Eq. 3 and the individual specimen misalignment $e$. The resulting effective notch $\mathrm{S}-\mathrm{N}$ curve is displayed in Fig. 12c; Table 6 lists the related values. Here, the statistical parameters are almost identical to the results of the structural stress approach. However, the scatter band in the high-cycle fatigue regime is still on a high level.

\section{Discussion}

All three investigated fatigue assessment approaches are within the finite life domain suitable to consider axial specimen misalignment. If the stress concentration is considered separately for every single specimen, a shift up to the fatigue performance of nominally offset-free specimens is observed. In the case of nominally offsetfree welded specimens, the separate consideration of each specimen's axial misalignment $e$ results in a minor increase of the FAT value and a decreased scatter band with a slightly reduced value of the inverse slope $k$. Therefore, even the comparably small offsets of technically plain specimens have a slight influence on the fatigue strength.

For the nominal stress approach, the $P_{\mathrm{S}}=97.7 \%$ lines of each misalignment fatigue strength level are almost congruent in the finite life domain suggesting a reasonably good agreement. However, the mean $P_{\mathrm{S}}=$ $50 \%$-lines show a slight rise in fatigue strength with axial misalignment indicating a slight overestimation of 


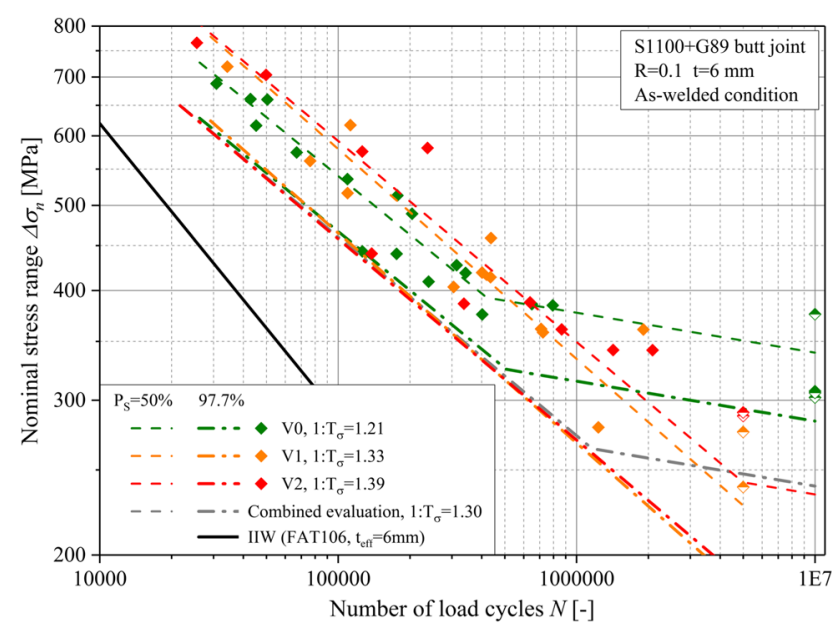

(a) Nominal stress approach

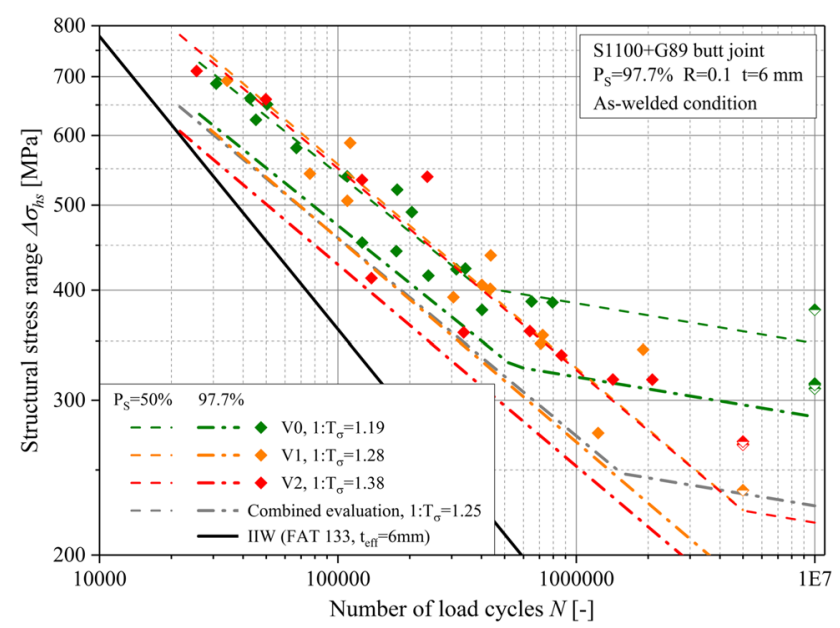

(b) Structural hot-spot stress approach

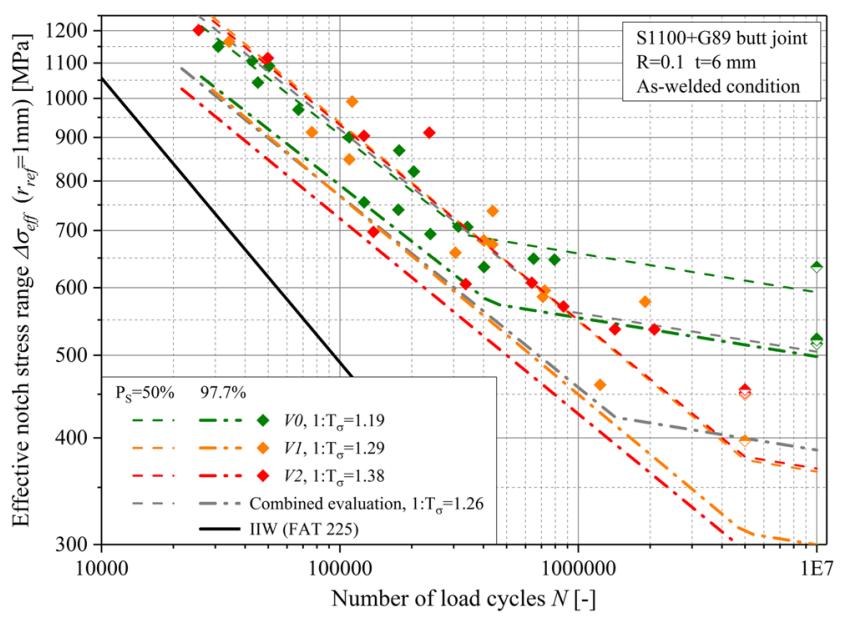

(c) Effective notch stress approach

Fig. 12 a-c Result of fatigue assessment in terms of S-N curves

the stress magnification. The congruency can be therefore traced back to this overestimation with a simultaneous increase in scatter band.
Structural and effective notch stress approach leads to a very good approximation of the 50\% survival probability in the finite life domain. The scatter bands of each misalignment level are similar and lower compared to the nominal stress approach. However, a rise with increasing offset value is still observable. This could be traced back to a quite strong dependency of the local weld topography on the axial misalignment, which is not covered within these investigations.

Each of these linear elastic approaches is based on a multiplication of the nominal stress with a cycle-to-failure independent misalignment factor. Therefore, a shift of the S-N curve's knee point $N_{\mathrm{k}}$ cannot be covered by this means. Therefore, none of the methods is thoroughly suitable for the assessment of the high-cycle fatigue domain. It is known that a shallow notch leads to a shift of the S$\mathrm{N}$ curve's transition knee points towards lower cycles $[30,31]$, but the IIW recommendations suggest a fixed knee point of ten million cycles. Hence, the evaluated data points match quite well in the finite life region, but exhibit some deviations in regions above two million load cycles.

\section{Effect of HFMI post-weld treatment on fatigue performance}

For the investigation of the effect of HFMI treatment on axially misaligned specimens, 16 specimens of offsetfree and eight specimens per misalignment grade V1 and V2 are tested. Thereby, the same test setup and data evaluation procedure as presented in Section 3 is used.

Figure 13 shows the resulting S-N curves for HFMItreated specimens; the corresponding values are given in Table 7. A direct comparison to the as-welded fatigue test results is provided by Fig. 14 displaying the statistically evaluated S-N curves. For all three misalignment levels, the post-weld treatment has a significant positive impact compared with the respective as-welded condition. The beneficial effect is observable in the finite life domain as well as the high-cycle fatigue region. As the number of specimens of series V1 and V2 is limited, the statistical analysis is not fully comprehensive. However, fundamental tendencies can still be observed. The applied post-weld treatment method increases the fatigue strength of the specimen with moderate offset up to the level of the offset-free HFMI-treated specimens. Apparently, the compressive residual stresses at the weld toe in combination with smoothening of the weld notch geometry are able to compensate a certain amount of axial misalignment. The fatigue resistance of the highly misaligned joints rises as well to the level of as-welded offset-free specimens. Based on these results, 
Table 6 Comparison of fatigue assessment methods, combined evaluation

\begin{tabular}{|c|c|c|c|c|c|c|c|c|c|c|c|c|}
\hline \multirow[b]{2}{*}{ Misalignment } & \multicolumn{4}{|c|}{ Nominal stress approach } & \multicolumn{4}{|c|}{ Structural stress approach } & \multicolumn{4}{|c|}{ Effective notch stress approach } \\
\hline & V0 & V1 & $\mathrm{V} 2$ & Comb. & V0 & V1 & $\mathrm{V} 2$ & Comb. & V0 & V1 & $\mathrm{V} 2$ & Comb. \\
\hline$k[-]$ & 4.5 & 4.2 & 4.4 & 4.4 & 4.6 & 4.3 & 4.4 & 4.5 & 4.6 & 4.3 & 4.4 & 4.5 \\
\hline $1: T_{\sigma}[-]$ & 1.21 & 1.33 & 1.39 & 1.30 & 1.19 & 1.28 & 1.38 & 1.25 & 1.19 & 1.29 & 1.38 & 1.26 \\
\hline FAT value $[\mathrm{MPa}]$ & 240 & 227 & 231 & 233 & 247 & 229 & 215 & 234 & 411 & 383 & 364 & 392 \\
\hline$\Delta \sigma_{\text {Run-out }}[\mathrm{MPa}]$ & 284 & - & - & 240 & 287 & - & - & 228 & 498 & - & - & 387 \\
\hline $1: T_{\sigma, \text { Run-out }}[-]$ & 1.27 & - & - & 1.42 & 1.29 & - & - & 1.43 & 1.26 & - & - & 1.41 \\
\hline
\end{tabular}

the HFMI post-weld treatment method is well applicable in order to counteract axial misalignment up to a certain amount.

The majority of HFMI-treated specimens reveal failure from weld toe. However, for these post-weld treated ultra high-strength steel joints, crack initiation is also observed from the weld root, sheet edges, pores or small weld splashes, even in case of specimens without misalignment.

In [32], recommendations regarding to upgrades of the fatigue strength resistance for HFMI post-treated highstrength steel joints are given. The guideline provides design proposals for the improvement in terms of numbers of FAT classes. Thereby, a benefit of one FAT class corresponds to an increase of $12.5 \%$ in FAT value. These upgrades are dependent on the yield strength of the base material stepwise starting with $\sigma_{\mathrm{y}}=355 \mathrm{MPa}$ up to the top level above $\sigma_{\mathrm{y}}=950 \mathrm{MPa}$. Furthermore, the inverse slope $k$ is set to a value of five for all post-weld treated joints. For the present S1100 butt joints assessed in nominal stresses, the guideline proposes an increase of eight FAT classes corresponding to a factor of about 2.57.

For specimens without axial misalignment, an increase of $37 \%$ compared with the as-welded fatigue strength is observed. This corresponds to an actual upgrade of about three FAT classes. The post-weld treated misaligned series V1 and V2 show an increase of just above $80 \%$ in FAT value compared with their as-welded fatigue strength. Here, the actual increase in FAT classes is about five. Thus, the resulting actual improvement is less pronounced than the proposed upgrade. However, this circumstance can be traced back to the fatigue strength of the as-welded specimens initially exceeding the respective FAT values recommended by IIW
Fig. 13 Fatigue test results of HFMI-treated specimen

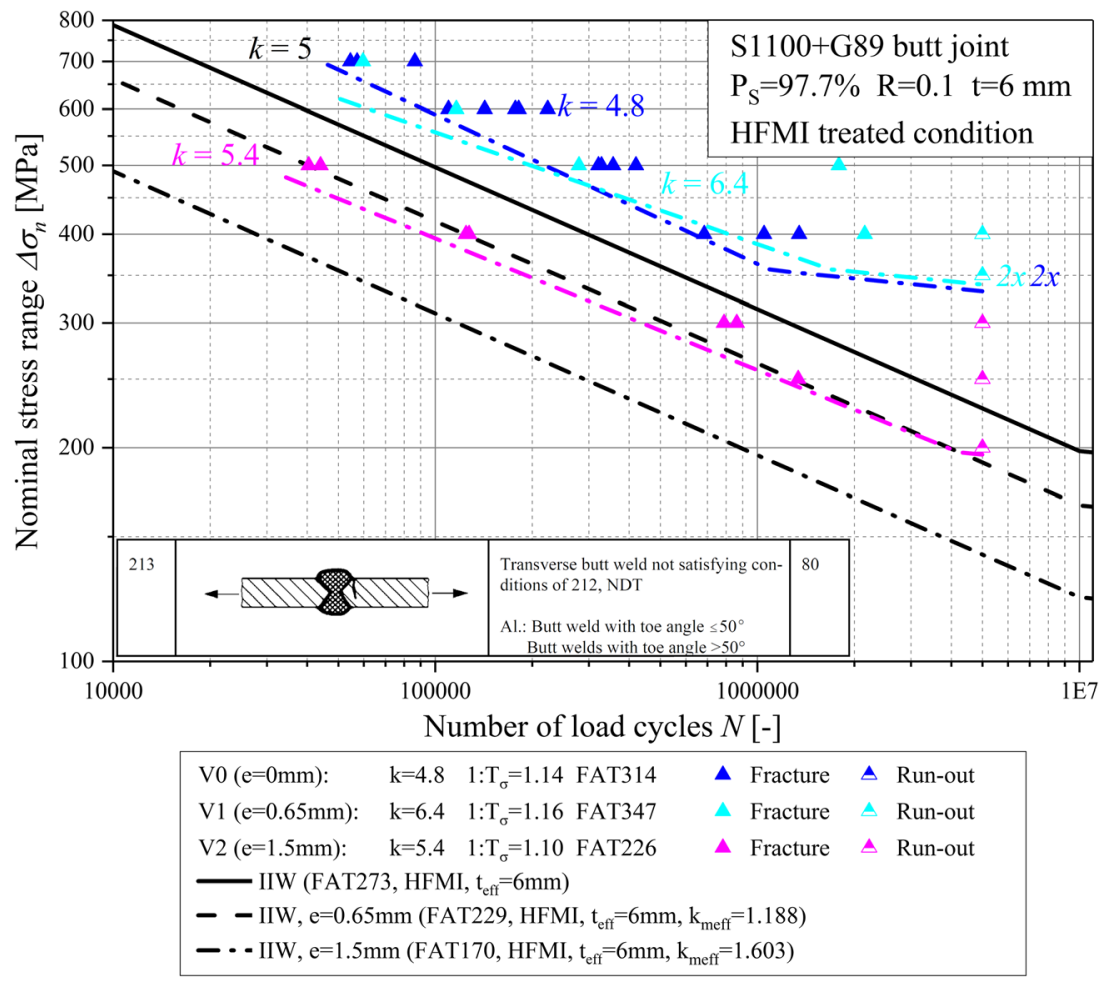


Table 7 Summary of the fatigue test results in HFMI-treated condition

\begin{tabular}{|c|c|c|c|c|c|c|c|c|}
\hline \multirow[t]{2}{*}{$\begin{array}{l}\text { Misalignment } \\
\text { level }\end{array}$} & \multirow[t]{2}{*}{$\begin{array}{l}\text { Weld toe } \\
\text { treatment }\end{array}$} & \multirow{2}{*}{$\begin{array}{l}\text { Inverse } \\
\text { slope } k \\
{[-]}\end{array}$} & \multirow{2}{*}{$\begin{array}{l}\text { Scatter } \\
\text { index } \\
1: T_{\sigma}[-]\end{array}$} & \multirow{2}{*}{$\begin{array}{l}\text { Transition knee } \\
\text { point } N_{k}[-] \\
\left(P_{\mathrm{S}}=97.7 \%\right)\end{array}$} & \multicolumn{2}{|c|}{ FAT value } & \multicolumn{2}{|c|}{$\begin{array}{l}\Delta \sigma_{\text {run-out }} \\
\left(P_{\mathrm{S}}=97.7 \%\right)\end{array}$} \\
\hline & & & & & (MPa) & $(\%)$ & $(\mathrm{MPa})$ & $(\%)$ \\
\hline V0 & HFMI & 4.8 & 1.14 & $1,100,000$ & 314 & 100 & 332 & 100 \\
\hline V1 & HFMI & 6.4 & 1.16 & $1,700,000$ & 347 & 111 & 339 & 102 \\
\hline V2 & HFMI & 5.4 & 1.10 & $4,200,000$ & 226 & 72 & 196 & 59 \\
\hline
\end{tabular}

significantly. The inverse slopes of all three S-N curves are in good agreement to the suggested value. The numbers to this paragraph are provided in Table 8 .

The suggestions for improvement due to HFMI postweld treatment in [32] are intended to be based on the initial FAT values suggested in the IIW guideline. Here, the proposed increase of eight FAT classes upgrades FAT106 to FAT273. This value is in very good accordance with the fatigue test results of the specimens without misalignment. The upgrades for misaligned specimens from FAT89 to FAT229 and FAT66 to FAT170 are clearly below the test results. This circumstance definitely confirms the proposed improvements in [32] for the present case. The consequential fatigue resistance S-N curves are illustrated in Fig. 13 enabling direct comparison to the fatigue test results; the data is again provided in Table 8 .

\section{Conclusions}

Ultra high-strength steel butt joint specimens are manufactured exhibiting different amounts of axial misalignment. Subsequent measurements confirm three significantly varying axial misalignment values; in detail 0,10 and $25 \%$ of sheet thickness. The angular distortion of the as-welded specimens naturally shows positive values corresponding to a bending towards the weld reinforcement. An additional HFMI treatment leads to a slight negative shift of the angular specimen distortion.

Fatigue tests in as-welded condition reveal a significant influence of axial misalignment on both finite life domain as well as high-cycle fatigue region. This can be traced back to secondary bending introduced by the axial offset. The effect is supported by the detrimental change of the local weld topography due to sheet offset. Specimens exhibiting a high offset at about $25 \%$ of
Fig. 14 Comparison of statistically evaluated S-N curves for as-welded and HFMI-treated condition

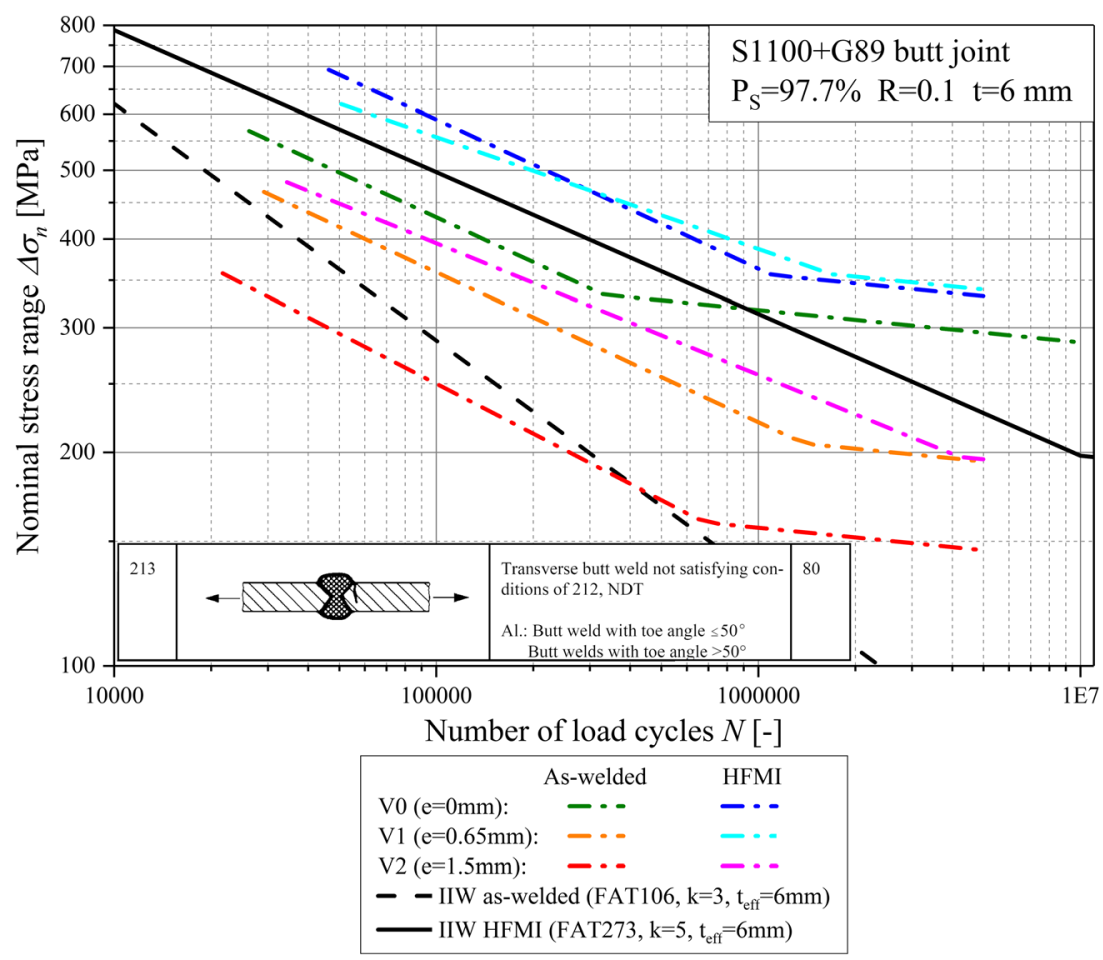


Table 8 Assessment of the improvement of the fatigue strength by HFMI post-weld treatment

\begin{tabular}{|c|c|c|c|c|c|c|c|}
\hline \multirow{2}{*}{$\begin{array}{l}\text { Misalignment } \\
\text { level }\end{array}$} & \multirow{2}{*}{$\begin{array}{l}\text { FAT value } \\
\text { as-welded }\end{array}$} & \multirow{2}{*}{$\begin{array}{l}\text { FAT value } \\
\text { HFMI }\end{array}$} & \multicolumn{2}{|l|}{ Improvement } & \multirow{2}{*}{$\begin{array}{l}\text { FAT value as-welded } \\
\text { according to IIW }\end{array}$} & \multicolumn{2}{|c|}{ Suggested upgrade for HFMI according to IIW } \\
\hline & & & FAT value $(\%)$ & FAT classes & & FAT classes & FAT value (MPa) \\
\hline V0 & 229 & 314 & 37 & 2.7 & 106 & 8 & 273 \\
\hline V1 & 191 & 347 & 82 & 5.1 & 89 & 8 & 229 \\
\hline $\mathrm{V} 2$ & 123 & 226 & 84 & 5.2 & 66 & 8 & 170 \\
\hline
\end{tabular}

sheet thickness cannot be treated using the nominal, IIW-recommended FAT values without special consideration of the misalignment.

Numerical investigations based on the effective notch stress concept utilising a fictitious reference radius of $r_{\text {ref }}=1 \mathrm{~mm}$ are carried out additionally. The geometric shape deviations of the joint are taken into account by individual numerical studies per specimen. These linear elastic finite element simulations show a linear increase of stress concentration factor with the axial offset value. In numbers, an offset of about a quarter of sheet thickness leads to a distinctive increase of local stresses at about $68 \%$. Furthermore, the numerical results are used to calculate the structural hot-spot stress magnification of each specimen type. A comparison of these values to analytical results indicates that the IIW-recommended restraint factor $\lambda$ for fully restrained clamps may overestimate the stress concentration. Especially for high ratios between clamping jaw distance and sheet thickness a deviation is observable. In such cases, the use of the restraint factor for unrestrained clamps leads to more coinciding results.

The fatigue assessments based on nominal, structural and effective notch stress approach taking into account the sample-dependent misalignment factor as stress magnifier are performed. The evaluation based on nominal stresses in combination with the suggested stress magnification factors for axially misaligned joints slightly overestimates the stress magnification of the misaligned joints in the finite life domain. The scatter range of the combined evaluation of all specimens gets narrower with a value of $1: T_{\sigma}=1.30$. Structural and effective notch stress approaches according to IIW lead to an even more improved scatter range of $1: T_{\sigma}=1.26$.

Summing up, the axial misalignment results in increased local stress concentration factors due to a change in geometry and additional secondary bending under loading. This affects the scatter band with nominal, structural and notch stress-based evaluation. The proposed equations for structural and notch stresses support an improved fatigue strength assessment of axially misaligned high-strength steel joints referencing a seam without alignment errors.

Fatigue tests with HFMI post-weld treated specimens of various misalignment levels indicate that due to the applied post-treatment method, a certain amount of axial misalignment may be tolerated without any reduction in fatigue strength compared to offset-free HFMI post-weld treated specimen. In numbers, for specimens exhibiting an axial misalignment up to $15 \%$ of sheet thickness no considerable deviation regarding to fatigue strength compared to the offset-free specimens is observed. The assessment of these fatigue test results reveals that the IIW recommendations for HFMI treatment lead to satisfactory conservative results if recommended FAT values are used. If the improvement from the actual aswelded to the HFMI fatigue test results is considered, the upgrade is far less pronounced compared with the proposal in the guideline.

Acknowledgements Special thanks are given to industry partner for the supply of material and the fabrication work done.

Funding information Open access funding provided by Montanuniversität Leoben.

Open Access This article is distributed under the terms of the Creative Commons Attribution 4.0 International License (http:// creativecommons.org/licenses/by/4.0/), which permits unrestricted use, distribution, and reproduction in any medium, provided you give appropriate credit to the original author(s) and the source, provide a link to the Creative Commons license, and indicate if changes were made.

\section{References}

1. Hobbacher A (2016) Recommendations for fatigue design of welded joints and components. Springer, 978-3-319-23757-2

2. Berge S, Myhre H (1977) Fatigue strength of misaligned cruciform and butt joints. Nor Marit Res 5(1):29-39

3. Cui W, Wan Z, Mansour AE (1999) Stress concentration factor in plates with transverse butt-weld misalignment. J Constr Steel Res 52(2):159-170

4. Lotsberg I (2009) Stress concentrations due to misalignment at butt welds in plated structures and at girth welds in tubulars. Int J Fatigue 31(8-9):1337-1345 
5. Liu X, Song W, Yan Z, Qiang W, Pan H (2016) Misalignment effect on stress concentration of thickness mismatched plate structures. Procedia Structural Integrity 2:2038-2045

6. Iwata T, Matsuoka K (2008) Misalignment effect on fatigue strength of CP titanium butt-welded joints. IIW-Doc. XIII-2234-08

7. Iida K (1977) Effect of misalignment in welded joint on low cycle fatigue strength of hemispherical pressure vessel made of $60 \mathrm{~kg} / \mathrm{mm}^{2}$ grade high tensile strength steel. IIW-Doc. XIII-815-77

8. Wylde JG (1979) The effect of axial misalignment on the fatigue strength of transverse butt welded joints, TWI industrial member report summary 99/1979

9. Maddox SJ (1985) Fitness-for-purpose assessment of misalignment in transverse butt welds subject to fatigue loading. IIW-Doc. XIII1180-85

10. Maddox SJ (1991) Fatigue strength of welded structures. Elsevier Ltd; Abington Publishing, Cambridge, p 1-85573-013-8

11. Andrews RM (1996) The effect of misalignment on the fatigue strength of welded cruciform joints. Fatigue Fract Eng Mater Struct 19(6):755-768

12. Alferov VI, Matskevich VD (1974) Investigation of technological errors in welded ship hulls assembly joints. IIW-Doc. XIII-761-74

13. Jakubczak H, Glinka G (1986) Fatigue analysis of manufacturing defects in weldments. Int J Fatigue 8(2):51-57

14. Goyal R, Glinka G (2013) Fracture mechanics-based estimation of fatigue lives of welded joints. Weld World 57(5):625-634

15. DIN EN ISO 5817 (2014) Welding - fusion-welded joints in steel, nickel, Titanium and their alloys (beam welding excluded) - quality levels for imperfections

16. Lieurade H-P, Huther I, Maddox SJ (2006) Recommendations on the fatigue testing of welded components. IIW-Doc. XIII-2140-06

17. Ottersböck MJ, Leitner M, Stoschka M (2016) Fatigue strength of fillet welded specimens focussing on angular distortion. IIW-Doc. XIII-2634-16

18. ASTM E739 (1991) Standard practice for statistical analysis of linear or linearized stress-life (S-N) and strain-life (e-N) fatigue data

19. Dengel D, Harig H (1980) Estimation of the fatigue limit by progressively-increasing load tests. Fatigue Fract Eng Mater Struct 3(2):113-128

20. Sonsino CM (2007) Course of SN-curves especially in the highcycle fatigue regime with regard to component design and safety. Int J Fatigue 29(12):2246-2258
21. Ottersböck MJ, Leitner M, Stoschka M (2015) Effect of loading type on welded and HFMI-treated T-joints. IIW-Doc. XIII-2584-15

22. Cerit M, Kokumer O, Genel K (2010) Stress concentration effects of undercut defect and reinforcement metal in butt welded joint. Eng Fail Anal 17(2):571-578

23. Fricke W (2012) IIW recommendations for the fatigue assessment of welded structures by notch stress analysis. WP Woodhead Publ, Oxford 9780857098566

24. Sonsino CM, Fricke W, de Bruyne F, Hoppe A, Ahmadi A, Zhang G (2012) Notch stress concepts for the fatigue assessment of welded joints - background and applications. Int J Fatigue 34(1):2-16

25. Morgenstern C, Sonsino CM, Hobbacher A, Sorbo F (2006) Fatigue design of aluminium welded joints by the local stress concept with the fictitious notch radius of $\mathrm{rf}=1 \mathrm{~mm}$. Int J Fatigue 28(8): 881-890

26. Baumgartner J, Bruder T (2013) An efficient meshing approach for the calculation of notch stresses. Weld World 57(1):137-145

27. Ottersböck MJ, Leitner M, Stoschka M (2018) Impact of angular distortion on the fatigue performance of high-strength steel T-joints in as-welded and high frequency mechanical impact-treated condition. Metals 8:302

28. Huther M, Henry J, Parmentier G (1992) Hot spot stress in cyclic fatigue for linear welded joints. International Institute of Welding, Paris

29. Niemi E, Fricke W, Maddox SJ (2006) Fatigue analysis of welded components - designer's guide to the structural hot-spot stress approach. Woodhead Publishing Ltd, Cambridge

30. Hensel J, Nitschke-Pagel T, Schönborn S, Dilger K (2012) Factors affecting the knee point position of S-N curves of welds with longitudinal stiffeners. IIW-Doc. XIII-2441-12

31. Hensel J, Nitschke-Pagel T, Dilger K (2012) Fatigue performance of welded steel longitudinal stiffeners. In: Chung JS (ed) The proceedings of the twenty-second (2012) International Offshore and Polar Engineering Conference. International Society of Offshore and Polar Engineers, Cupertino, Calif

32. Marquis GB, Barsoum Z (2016) IIW recommendations for the HFMI treatment. Springer Singapore, Singapore 9789811025037

Publisher's note Springer Nature remains neutral with regard to jurisdictional claims inpublished maps and institutional affiliations. 